\title{
EL INDIVIDUO ANTE LA ÉTICA PÚBLICA
}

\author{
Javier MUGUERZA \\ UNED
}

Puesto que lo que se ventila en el presente texto es, de algún modo, el problema de la interrelación de lo público y lo privado, quizás fuera oportuno comenzarla recordando la célebre Fábula de las abejas del médico holandés Bernard de Mandeville, aparecida en inglés, como el resto de su obra, en 1714: The fable of the bees; or private vices, public benefits, compendio de su adjunta Inquiry into the origin of moral virtue ${ }^{1}$.

¿En qué consistía la fábula de Mandeville? Tal y como ésta ha sido generalmente leída, la fábula se habría atrevido a insinuar que - por más que los hombres sean egoístas e insolidarios- el egoísmo y la insolidaridad humanos no tendrían por qué llevar al desastre a la sociedad, a la que podrían, antes bien, servir de gran provecho. Contra lo que aseguraba la teoría de los sentimientos morales de Shaftesbury o Hutcheson, el panal en que vendría a consistir la vida social no se halla regido por la mutua simpatía de sus habitantes, que para Mandeville no pasaban de constituir «un conjunto de bribones». Por el contrario, la vida social se basa en la cruda búsqueda del interés particular por parte de los miembros de la sociedad, si bien lo que sucede es que la sociedad en su conjunto puede alcanzar por esa vía la felicidad y la prosperidad, toda vez que, al intentar aquellos miembros obtener beneficios privados por medio de su actividad, acaban asímismo generando beneficios públicos. Así ocurría con las abejas de la fábula, prósperas y felices a pesar $\longrightarrow$, mejor dicho,

1 Hay traducción española de la edición de F. B. KAYE (1924) por José FERRATER MORA, México, 1982. 
a causa - de sus vicios, pues la ambición, el afán de lucro o la afición al lujo les habían llevado a construir un Estado "cuyos pecados", según escribe Mandeville, "contribuían a hacerlo grande". Hasta que un buen día Júpiter, indignado ante la hipócrita exaltación de la virtud a que los moradores del panal se entregaban con el fin de ocultar su falta de honradez o simplemente molesto por la falta de perspicacia que les impedía reconocer que la perfección a la que alardeaban de aspirar es más de lo que los dioses pueden otorgar a sus criaturas, decidió convertirlos en verdaderamente virtuosos... lo que ocasionó la ruina de semejante sociedad, que tan bien funcionaba cuando sus ciudadanos eran viciosos. Pues, como concluye la fábula, "sólo los tontos se esforzarían por hacer de un gran panal un panal honrado". Hasta aquí la fábula, cuya interpretación - como suele ocurrir con cualquier texto filosófico- ha generado, sin embargo, ríos de tinta. ¿Pretendía Mandeville, al escribirla, consumar una apología de la inmoralidad, o fue su intención bastante más moralizante de lo que aparenta?

Algunos intérpretes de su obra han apuntado que lo que Mandeville se proponía era, en rigor, llevar a cabo una crítica de la hipocresía de la naciente sociedad burguesa, esto es, del desajuste entre los principios morales que teóricamente la inspiraban y las prácticas morales o, mejor dicho, inmorales que eran habituales en su seno. Mas si ése fué, en verdad, el propósito de Mandeville, lo cierto es que el tiro le salió por la culata y su fábula sería entendida precisamente del revés: el cínico lema Vicios privados, públicos beneficios (e incluso públicas virtudes, pues la idea de "beneficio» llegaría a resultar sinónima de la de "virtud») hizo fortuna al margen de las previsiones del autor, cualesquiera que éstas pudieran haber sido. En efecto, y como todo el mundo sabe, el lema de Mandeville vendría a transformarse en ingrediente clave de una influyente teoría política y económica, la del liberalismo clásico, pues se halla tras la hipótesis de la "mano invisible» de Adam Smith, encargada de convertir en orden el caos social alimentado por el capitalismo. Y hasta cabría decir que, en líneas generales, se transformaría en un epítome de la moral burguesa: el mismísimo Kant, bastante más realista en su filosofía social y de la historia que a la hora de ocuparse de la ética, llegó a hablar de la "insociable sociabilidad" de los hombres, cuyos impulsos contrapuestos se neutralizarían unos a otros en el seno de la sociedad, produciendo, en último término, el bien a partir del mal (una teodicea ésta secularizada o disfrazada de sociodicea que preludia a su vez el recurso de Hegel a la "astucia de la razón», la hegeliana List der Vernunft, por la que la Razón, como el Dios de los teólogos que había venido 
a secularizar la Ilustración, se encargaría de trasmutar el mal en bien social). Quizás esta interpretación de Kant, si es que no las de Smith o Hegel, sea aún más abusiva que la usual de Mandeville, pero, como antes se advertía, con las ideas de los filósofos ocurre con frecuencia que adquieren vida propia, y no es del todo ilegítimo juzgarlas por sus efectos al menos tanto como por la intenciones de quienes las pusieron en circulación.

Comoquiera que sea, Mandeville no nos interesaba por sí mismo, sino sólo como pretexto para hablar de virtudes y vicios en nuestra sociedad, que es, eso sí, una sociedad heredera de la suya. Nuestra sociedad, para bien o para mal, procede de la descrita por Mandeville, aun cuando hoy nos mostremos más reacios a compartir el optimismo - si cabe llamarlo así- que en los albores del siglo XVIII permitía hacer virtud de la necesidad, es decir, del vicio. En nuestros días, en cualquier caso, no se habla tanto de los vicios de la privacidad cuanto de sus virtudes, fenómeno encuadrable bajo el rótulo del llamado auge de la privacidad o predominio de la "moral privada" sobre la "moral pública", con frecuencia asociado, de modo un tanto confundente, a lo que asímismo se ha dado en llamar el retorno del individuo o "neoindividualismo": la confusión procede en este punto de lo que se desee entender por individuo, cuyo aposentamiento en "el ámbito íntimo" habría venido siendo teorizado a partir de esos clásicos del pensamiento político que fueron Hobbes y Locke - pasando por Tocqueville, Mill, Simmel, etcétera - hasta arribar a los teóricos contemporáneos de "la ascensión del hombre privado", que discurren, como se sabe, desde sociólogos como Richard Sennet a escritores de más difícil clasificación como Christopher Lasch ${ }^{2}$. A lo largo de dicha trayectoria, no ha faltado quien aprecie una suerte de ruptura de sentido, esto es, una ruptura entre el sentido - eminentemente positivo- que tuvo un día aquella noción y el que, con más o menos justificación, ha acabado cobrando en los últimos tiempos. Pero quizás también quepa dar cuenta de ese mismo proceso en términos de continuidad, una continuidad degenerativa, si se quiere, pero continuidad al fin.

De acuerdo con la tesis "rupturista", el mundo privado representaba para un Hobbes o un Locke el baluarte de los fueros del individuo -el lugar de la "libertad de los modernos", para decirlo con la terminología ulteriormente

2 Cfr. Helena BÉJAR, El ámbito intimo (Privacidad, individualismo y modernidad), Madrid, 1988. 
acuñada por Benjamin Constant, quien la hacía descansar en el importantísimo pilar de la libertad de conciencia-, baluarte desde el que el individuo se vería luego catapultado a la conquista de la esfera pública. Tal y como hoy lo ven, en cambio, Sennet o Lasch, cada uno a su manera y al margen de sus respectivas valoraciones, el mundo privado vendría más bien a ser el último refugio al que el individuo se repliega impotente, tras de abandonar la esfera públi$\mathrm{ca}$, para entretener allí su inanidad con la entrega a los esparcimientos de la "cultura narcisista". Ahora bien, si el punto de partida de semejante evolución hubiera que buscarlo en esa variante hobbesiana o lockeana del individualismo burgués que Crawford Macpherson bautizó como «individualismo posesivo» - un individualismo carente de otras metas que la consecución del propio interés-, tal vez no haya mayor dificultad en conceder a los partidarios de la tesis "continuista" que de los polvos de ese individualismo sólo podían salir los lodos de que nos hablan actualmente Lasch o Sennet.

Y lo que acaba de decirse, en la esfera privada, del individualismo de Hobbes y Locke podría también ser dicho, por lo que se refiere al mundo público, de esa otra cara del individualismo de ambos pensadores en que consistiría a la postre su "contractualismo". Pues su teoría del contrato social constituye, en algunos de sus designios por lo menos, una pieza de doctrina tendente a garantizar desde el Estado - y es de importancia secundaria en este punto que se trate de un Estado absolutista o liberal - la seguridad de los individuos $y$, ante todo, el respeto de su propiedad privada en tanto que atributo decisivo de su "privacidad". Lo que podría, a su vez, llevar a sugerir que de los polvos de tal contractualismo sólo podían salir, en nuestro siglo, los lodos del neocontractualismo de un James Buchanan o un Robert Nozick, para quienes hasta el tímido redistribucionismo de los ingresos y las cargas sociales en la "sociedad del bienestar" constituye un estorbo a remover de su proyecto de legitimación del Estado capitalista sobre las bases de un neoliberalismo radical. La pregunta es si no hay otro contractualismo, como también, por cierto, otro individualismo, del que enseguida habremos de ocuparnos ${ }^{3}$. En cuanto a ese otro contractualismo, sus raíces habrían de ser buscadas en el Rousseau teórico de una democracia más o menos participativa que, sin por ello renegar necesariamente de la libertad de los modernos de Constant, reivindicaría lo

3 Véanse sobre este punto "Entre el liberalismo y el libertarismo" y "Sobre la racionalidad o irracionalidad de la justician, capítulos 5 y 24 de mi libro Desde la perplejidad, MéxicoMadrid-Buenos Aires, 1990. 
que el propio Constant llamó la "libertad de los antiguos", esto es, la libertad destinada a permitir la plena participación de los ciudadanos en la vida política según el modelo - por lo demás, un tanto idealizado- de la CiudadEstado o la república grecorromana. Una «tradición» ésta rousseauniana de la que hoy pervive al menos algo en neocontractualismos del estilo de un John Rawls o un Jürgen Habermas, especialmente el del segundo, sin duda más proclive al republicanismo que el primero.

Pero, volviendo al individualismo, ¿qué podríamos decir de los teóricos del auge de la privacidad, como Sennet o Lasch? En rigor, tanto uno como otro se limitan a constatar la debilidad del individuo - del "yo", para decirlo en los términos freudianos que les son caros- recluído en el mundo privado. Y lo que respectivamente propugnan Lasch o Sennet es o bien reforzar su superego o bien abrir las puertas de su ello. Ahora bien, del partido del "superego" al que enfáticamente adhiere Lasch, con su reivindicación nada menos que de "la familia", se ha podido comentar que apesta a un tufo - por decirlo piadosamente- «neoconservador», mientras que el partido del "ello" al que desfallecientemente adhiere Sennet - con su reivindicación de la "ciudad anárquica» y otras lindezas- produce la impresión de una anacrónica flor sesentayochista, ajada y marchita ya como no podía menos de ocurrir al cabo de cinco lustros largos del 68. El partido que, a mi modo de ver, habría en estos momentos que reivindicar no es el del ello ni el del superego, sino el del yo autónomo y responsable que en la literatura filosófica se identifica desde Kant, si es que no desde Sócrates, con el sujeto moral. $\mathrm{O}$, con otras palabras, el individualismo a propugnar sería lo que cabría llamar acaso un individualismo "ético». Es decir, un individualismo que, a tenor de ese calificativo, respondería a un concepto normativo de individuo, encerrando una propuesta moral relativa a lo que el individuo debiera ser más bien que una descripción de lo que el individuo es actualmente, pues lo que el individuo es actualmente tal vez no esté muy lejos de la descripción o el diagnóstico de los teóricos del auge de la privacidad.

Cuando se habla hoy del auge de la privacidad o, lo que es más, de la privacidad como virtud, lo que se está diciendo es simplemente que los individuos que todos nosotros somos acostumbramos a refugiar en tal privacidad nuestra impotencia como ciudadanos, tras sentirnos excluidos o excluirnos de una publicidad viciosamente concebida. Rotos los nexos que, mejor o peor, en otros tiempos conectaban privacidad y publicidad, mundo privado y esfera pública, aquél sería, como dijimos, "el último refugio" que nos queda, la última línea 
de repliegue que -en lugar de servirnos ya de catapulta para lanzarnos a participar en la vida política - nos permite sustraernos, en un movimiento exactamente inverso al de nuestros ancestros, a una vida política regida por aparatos que nos son ajenos, en los que nos está vedada una auténtica participación, de los que no podemos sentirnos protagonistas. $\dot{Y}$ a esa retaguardia retrocedemos empujados por los vicios de una publicidad cuya inmediata consecuencia es el alejamiento o retraimiento del individuo respecto de las actividades del Estado, esto es, su ostracismo en el mundo privado. En éste el individuo es libre aún, pero apenas para otra cosa que para cultivar sus hobbies y contemplar su vídeo y su televisor, con una libertad no inventariada por Constant a la que se podría denominar no enteramente en broma $-y$ para distinguirla por igual de las de antiguos y modernos - la «libertad de los postmodernos». Para decirlo resumidamente, la otra cara del auge de la privacidad vendría ahora a ser lo que se suele conocer como el declive de lo público, declive que, cuando lo público se identifica con el Estado y su declive es percibido como positivo, recibe el nombre, en paralelo al del retorno del individuo antes mentado, de retorno de la sociedad civil.

El término «sociedad civil» no es menos ambiguo que el término «individuo", y enseguida tendremos ocasión de mencionar algunas de esas ambigüedades. Pero, por el momento, nos serviremos de él en el sentido en que lo hacen los teóricos de su retorno, que suelen provenir del ámbito ideológico liberal-conservador y proceden a criticar la -en su opinión-creciente "estatalización" de la vida social en la ya aludida sociedad del bienestar, esto es, la sociedad regida por el Estado "benefactor" o welfare State ${ }^{4}$ : de semejante Estado dependen, en efecto, muchas cosas en tales sociedades, desde la atención a la sanidad o la educación públicas al control hacendístico de la economía, pasando por la tutela del sistema productivo en conexión con sindicatos y organizaciones empresariales, además, claro está, del mantenimiento del ejército y las restantes fuerzas de seguridad nacional. Son demasiadas tareas para el Estado al decir de sus críticos procedentes de la derecha, que no acostumbran a reconocer tan fácilmente que algunas de ellas se limitan a aliviar a la empresa privada de buena parte de los costos sociales de la producción, así como a garantizar la paz social que la hace posible mediante la

4 Cfr., a título de muestra, los libros de Víctor Pérez DiAz, El retorno de la sociedad civih Madrid, 1987 y La primacía de la sociedad civil, Madrid, 1993. 
corrección de graves injusticias que el viejo Estado liberal se había mostrado incapaz de superar.

Para los denostadores de aquel supuesto exceso estatalizador, el Estado intervencionista debiera eclipsarse y confiar exclusivamente al mercado la resolución de los problemas del desarrollo y la distribución de la riqueza, de suerte que el retorno de la sociedad civil se manifestará, para empezar, en la exigencia de una política de "privatización económica" tendente a recortar las atribuciones estatales en lo relativo a la producción de bienes y servicios (una política, por cierto, que en modo alguno ha sido exclusiva de gobiernos conservadores, como los ingleses y norteamericanos de décadas atrás, sino que asimismo se ha visto practicada, con el fervor incluso del neófito por no pocos gobiernos socialistas o sedicentemente tales. $Y$ algo por el estilo cabría decir de los indicios de privatización que se registran en el dominio del derecho no menos que en el de la economía, "privatización jurídica" ésta reflejada en la tendencia a la desregulación que trata de liberar al sistema legal de sobrecargas, mitigando la intervención legislativa del Estado en una serie de campos donde hasta ahora venía siendo considerada necesaria, cuando no imprescindible 5 . Pues, en efecto, la tendencia a la desregulación no se manifiesta tan sólo en la deseable despenalización de hipotéticos delitos que, como el juego o ciertos tipos de relaciones sexuales, descansan en un acuerdo contractual entre las partes que conjuntamente los cometen, sino que favorece asímismo la contractualización entre los interesados en ámbitos, como por ejemplo el de las relaciones laborales, donde la intervención del Estado tenía por cometido la protección jurídica de la parte más débil. En cuyo caso, la desregulación de dichas relaciones desiguales se traducirá en una mayor indefensión de aquella última, "privándola», pues también en eso consistiría la privatización, de los recursos que las leyes y el derecho pudieran aprestar en su defensa. Pero, por lo demás, la marea privatizadora se extiende por doquier. Y, así, no ha faltado quien añada un nuevo capítulo a las privatizaciones económica y política que se acaban de señalar, como vendría a ser el caso de la "privatización ideológica" o desideologización alentada por el postmodernismo ${ }^{6}$. Mas como no estoy del 11 y ss.

5 En relación con todo ello, cfr. Nicolás LOPEZ CALERA, Yo, el Estado, Madrid, 1992, págs.

6 LÓpez Calera, op. cit., menciona a este respecto la obra de Alex Callanicos Against Postmodernism (A Marxist Critique), Cambridge, 1989, cuya caracterización de los "postmodernos" como "los hijos de Marx y de la Coca-Cola" (the children of Marx and Coca-Cola) parece limitarse, sin embargo, a lamentar que tales «hijos" lo sean más de su madre que de su padre. 
todo convencido de que una tal denuncia de la "desideologización" no se escore a la añoranza de pasados «monolitismos» ideológicos, más bien que a la propuesta de una harto saludable "proliferación" de las ideologías, prefiero posponer para más adelante la discusión de este tercer aspecto de la cuestión (en el bien entendido de que lo que encuentro repudiable de la privatización ideológica es, justamente, la ideología de la privatización).

Recapitulando muy brevemente cuanto llevamos visto hasta el momento, se diría que las nociones de individuo y de sociedad civil que cimentaban la fábula de Mandeville continúan en rigor siendo las mismas en que se apoyan en la actualidad - al cabo de casi tres siglos- los teóricos tanto del wauge de la privacidad" como del «declive de lo público». Y de ahí que ambos fenómenos hayan podido ser descritos por los partidarios de esa manera de entender al individuo y a la sociedad como un "retorno" del uno y de la otra, esto es, como si nada hubiera cambiado desde el liberalismo clásico a nuestros días. Pero algo ha cambiado desde entonces acá y, por lo pronto, lo que ha cambiado es la percepción de que esa clásica manera de entender al individuo - y también a la sociedad civil- resulta insuficiente en nuestros días, o debiera al menos resultarlo, pues ni el individuo ni la sociedad civil parecen reducirse a lo que entienden por tales los administradores de la herencia de Mandeville.

Por expresarlo en dos palabras, ni el individuo se reduce al homo oeconomicus ni la sociedad civil se reduce a la civil society de los economistas, paleo o neoliberales; y así como el término "individualismo" podría reivindicar su extensión a la defensa de los fueros de ese individuo que es el sujeto moral, el homo moralis, también cabría emprender la reivindicación de que el término "sociedad civil" se extienda hasta cubrir otros muchos sectores sociales no incluidos en la denotación tradicional de dicho término; sectores que, por lo demás, han llegado a dar pie a la elaboración de una crítica de la sociedad del bienestar desde la izquierda, a no confundir con su crítica desde la derecha de que nos acabamos de hacer eco.

Por ejemplo, un teórico como Claus Offe, que se ha ocupado de las «contradicciones del Estado de bienestar», ha contrapuesto a la salida de esas contradicciones por la vía conservadora que hemos visto de la reprivatización económica, jurídica e ideológica - que era una vía consistente en despolitizar lo más posible la vida social, sustrayéndola a la acción del Estado- la alternativa de una vía progresista consistente precisamente en lo contrario, a saber, en la politización o repolitización de esa vida social por parte de los ciudadanos, 
pero, y aquí radicaría la novedad de su propuesta, al margen de los cauces institucionales suministrados por el Estado, como los partidos políticos y la democracia representativa, característicos de lo que un día diera en llamar "el viejo paradigma de la política» ${ }^{7}$. Al fin y al cabo, Offe contribuyó notablemente a la teorización de esos "nuevos movimientos sociales" -como el pacifismo, el feminismo o el ecologismo- en los que se creía apreciar algo así como «un nuevo paradigma", el paradigma de "la política no-institucional". Por lo que en concreto se refiere al Estado benefactor, los ciudadanos —es decir, individuos y agrupaciones de individuos - podrían, pongamos por caso, reclamar una mayor participación en el control de su gestión y, de este modo, contribuir a mitigar los efectos de su burocratización o su propensión a excluir de los beneficios de la prosperidad a los marginados o desafectos al sistema. Pero en lo que nos interesa ahora reparar es en que semejante nuevo paradigma de la política no sólo trata de "ensanchar el ámbito de la sociedad civil», sino asímismo de "acortar la distancia que la separa de la sociedad política", reproduciendo así la vieja aspiración rousseauniana de aproximar cuanto se pueda al "hombre» y al "ciudadano». Ello no debiera extrañarnos, puesto que Offe es un discípulo de Habermas, quien a su vez, y aun si muy moderadamente, se reclama de aquella herencia rousseauniana, otrora compartida tanto por anarquistas como por marxistas - lo que, ciertamente, da idea de que se trata de un equívoco legado-, si bien ni Offe ni Habermas - ni, por supuesto, los marxistas, que la arrinconaron en su práctica antes de descreer de ella en la teoría, y ni siquiera ya los anarquistas que puedan todavía sobrevivir - albergan grandes ilusiones acerca de una improbable identificación final de sociedad civil y Estado ${ }^{8}$, sobre la que por nuestra parte, en cualquier caso, habremos de retornar en su momento.

Pero lo que ha desaparecido, desde luego, de la escena política, incluida la política no-institucional, es the longing for total revolution, "el anhelo de una revolución total» que incluya un rediseño alternativo de la sociedad en su conjunto. Por el contrario, el "nuevo paradigma político" habría de caracterizarse por una serie de rasgos de los que alguna vez me he permitido des-

7 C. OfFE, "Los nuevos movimientos sociales cuestionan los límites de la política institucional", en Partidos políticos y nuevos movimientos sociales, Madrid, 1988, págs. 163-244; Contradicciones del Estado del Bienestar, Madrid, 1990.

8 Véase mi trabajo "Polis without politeia?", en W. KRAWIETZ y G. H. vON WRIGHT (eds.), Öffentliche oder private Moral? Festschrift für Ernesto Garzón Valdés, Berlín, 1992, págs. 215-30. 
tacar estos tres 9 . El primero de ellos, su negatividad. Para decir que "no" al mundo presente no es preciso tener ideas muy claras -como no las tenemos hoy - acerca del futuro, de la misma manera que para protestar contra el estado actual de nuestra sociedad no es preciso abonarse a un modelo social de recambio que, para colmo, hubiera de advenir indefectiblemente de acuerdo con el sesgo escatológico que la utopía revestía para el marxismo clásico. El segundo de aquellos rasgos del nuevo paradigma - que afecta, por lo pronto, a la manera como se habría de articular esa protesta negativa- es su fragmentarismo. Con la utopía erigida sobre los pilares de una filosofía escatológica de la historia, también se vino abajo la noción de un único "sujeto histórico" llamado a protagonizar con exclusividad o eminentemente las transformaciones sociales, como se pensaba era el caso del proletariado. Aquel sujeto se ha disgregado en los múltiples movimientos pacifistas, feministas, ecologistas, etc., de que hablábamos, movimientos en los que la protesta de hecho se fragmenta. El individuo apenas trata de incidir en el espacio público a través de movimientos organizados en torno a partidos políticos, cosa que sólo hace, cuando lo hace, ocasionalmente, con ocasión, por ejemplo, de unas elecciones. Y si su constancia en la afiliación a organizaciones sindicales, sin ser indesmayable, resulta ligeramente superior, no hay que olvidar que dichas organizaciones dejaron hace tiempo de actuar como simples correas de transmisión de algún partido. Cuando un partido, parlamentario o extraparlamentario, consigue sacar masas a la calle, lo consigue asímismo convocándolas con un objetivo parcial o puntualmente, como una manifestación en contra del racismo o la xenofobia. Y el propio espacio público, en fin, también ha sido en líneas generales parcelado, de suerte que el barrio, el lugar de trabajo o la Universidad cuentan hoy tanto o más a esos efectos que unidades más vastas como las de carácter nacional-estatal. Los mismos nacionalismos se mostrarán más vivos si se trata de nacionalidades que pugnan por su reconocimiento que de auténticas Naciones-Estado, sin que haya tampoco que olvidar que la noción de soberanía nacional se ha difuminado un tanto y que los medios de comunicación masiva son capaces de instalar directamente al individuo en cualquier punto de la «aldea global». El tercer y último rasgo a señalar es el de la importancia primordial que cobra a estos efectos la idea de disenso. En un cierto sentido,

9 Por ejemplo, en mi contribución «Un contrapunto ético: la moral ciudadana en los ochentan a J. M. GONZÁlEZ GARCIA y F. QUESADA (eds.), Filosofia política (número monográfico de la revista Arbor, 503-4, 1987), págs. 231-58. 
dicho rasgo parece un corolario de los dos anteriores, pues la idea de fragmentación era de algún modo ya antitética de la de consenso, mientras que la protesta negativa constituía de suyo una abierta manifestación de disenso. Sin embargo, y a mi entender, la idea de disenso es aún más fundamental que aquellas dos por lo siguiente: los movimientos negativos y fragmentarios de disensión de que se hablaba son movimientos protagonizados por grupos de individuos, lo que quiere decir ni más ni menos que ugrupos de individuos". Quien disiente es siempre, en última instancia, un individuo, y es por eso por lo que el disenso reviste la importancia ética, y no sólo política, que reviste, pues no en vano han de ser los individuos los protagonistas de la vida moral. $\mathrm{Y}$ en cuanto al individuo que se halla a la base de cualquier sujeto colectivo imaginable en el interior de la sociedad civil, le sería dado, por supuesto, insertarse a la vez en más de una colectividad. Una mujer, supongamos, podría verse a sí misma como militante de un movimiento feminista, pero eso no le impide interesarse a un tiempo por la paz o la ecología, así como afiliarse a un sindicato o pertenecer a una asociación de vecinos, esto es, adoptar una pluralidad de "posiciones de sujeto", para decirlo con la terminología de Ernesto Laclau y Chantal Mouffe ${ }^{10}$. Lo que la participación política procura a un individuo es la posibilidad de intervenir en las decisiones que afectan a su vida, la posibilidad de autodeterminarse en cada una de ellas, y la multiplicidad de las posiciones de sujeto adoptadas por el individuo «multiplica sus posibilidades de autodeterminación", aun si no necesariamente su capacidad real de autodeterminación, que evidentemente depende de factores que exceden a la voluntad individual, como los condicionamientos socioeconómicos que, por ejemplo, puedan limitar la libertad de decisión de ese individuo.

En cualquier caso, y cuando menos, le otorgará la posibilidad de "hacerse oír» en todos esos campos. Pues, como ha puesto de relieve Albert Hirschman, ni tan siquiera los actores del mercado se reducen a ese átomo mudo y sordo que es el homo oeconomicus, constreñido al intercambio de cantidades por precios con otros átomos sumidos en el silencio del anonimato: el individuo habla consigo mismo, pues sus diversas posiciones de sujeto le convierten en "polifónico"; pero habla también con los restantes individuos, con los cuales establece relaciones de cooperación y de conflicto, de suerte que sus "voces de lealtad o de protesta" transmiten tanta o más información que los precios, es decir,

10 Cfr. E. LaClau y Ch. Mouffe, Hegemonía y estrategia socialista. Madrid, 1987. 
permiten reducir en mayor medida que éstos la incertidumbre acerca de los estados futuros del mercado, contribuyendo incluso a transformarlos ${ }^{11}$; y lo que acaba de decirse del "hombre económico" cabría decirlo, a fortiori, del «hombre sociológico» o del «hombre político». Detrás de todos ellos se hallará invariablemente el sujeto moral autónomo, esto es, el «hombre moral».

En cuanto a los rasgos de negatividad, fragmentación o disenso que dimos en considerar característicos del nuevo paradigma político, serían abiertamente rasgos postmodernos o, como acaso fuera preferible calificarlos, «transmodernos» ${ }^{12}$, donde la transmodernidad daría a entender algo así como la Aufhebung de la modernidad, esto es, su superación y conservación a un mismo tiempo en lugar de su pura y simple liquidación postmodernista.

Comoquiera que ello sea, llámesela "postmodernidad" o "transmodernidad", lo que experimentamos hoy, gracias al nuevo paradigma, es una deflación del vocabulario político, así como del repertorio de significados a los que éste sirve de vehículo. En un reciente texto de Richard Rorty, entre otras cosas dedicado a comentar la traduccción inglesa de un par de obras de Laclau y Mouffe, se ha llamado muy oportunamente la atención sobre este hecho ${ }^{13}$. Así, cuando Rorty escribe por ejemplo: "Convengo con Laclau en sostener que no hay razón para creer en la existencia de un sujeto privilegiado en la "lucha anticapitalista" pero me gustaría corregir esta última expresión. No creo que "lucha anticapitalista" quiera decir hoy mucho, por lo que sugiero el desplazamiento de la expresión por otra trivial y ateórica, como, pongamos por caso, "lucha contra la miseria humana evitable". De modo general, confío en que sea posible la trivialización de todo nuestro vocabulario izquierdista. Sugiero que comencemos a hablar de "codicia y egoísmo" en lugar de "ideología burguesa", de "raciones de hambre y de despidos" en lugar de "valor de la fuerza de trabajo", de "gasto diferencial por alumno en las escuelas" o de "acceso diferencial a los cuidados de la salud" en lugar de "la división de la sociedad en clases"".

11 Cfr. A. HiRSCHMAN, Salida, voz y lealtad, México, 1977; Interés privado y acción pública, México, 1986; Enfoque alternativos sobre la sociedad de mercado, México, 1989 (véase asímismo Enrique GIL Calvo, "El arte de navegar contra el viento", Claves, 20, 1992, págs. 24-31).

12 Tomo este término de Rosa María Rodriguez Magda, la sonrisa de Saturno, Valencia, 1991.

13 R. RORTY, "Esperanza social e historia», Babel, 1, 1992, págs. 15-24. 
Según se echa de ver, el precedente es un texto provocativo, como acostumbran a serlo los de ese "provocador" nato que pasa por ser Rorty. $\mathrm{Y}$, a decir verdad, no estoy nada seguro de que baste por sí solo para arruinar el análisis económico, sociológico o político de la vida social de inspiración marxista. Mas lo que Rorty llama ahí la "trivialización" del vocabulario político concede, en cambio, a la categorización moral de aquellos fenómenos al menos tanta relevancia como la concedida por el análisis marxista a las categorías procedentes de la economía, la sociología o la política... y eso, si he de ser sincero, no me parece mal del todo.

Antes de concluir con este punto, digamos algo todavía sobre la relación entre el viejo y el nuevo paradigma de la política, que no carece, como vemos, de implicaciones éticas. En los últimos años, Offe —que no es ya el Offe de su obra pionera sobre los partidos políticos y los nuevos movimientos socialesha mitigado un tanto la contraposición entre ambos paradigmas, y hasta tiende a rehuir esta palabra, que podría dar idea de incompatibilidad donde lo que hay más bien es complementariedad entre dos modos de abordar lo que llamamos "la política" 14: si por viejo paradigma entendemos, en efecto, "Estado democrático y partidos políticos», el nuevo paradigma de "la política no-institucional" no ha acabado con ellos. Pues lo cierto es que los partidos políticos continúan siendo hoy por hoy un mal necesario, donde habría que subrayar con igual énfasis el sustantivo y el adjetivo, y otro tanto habría que decir del mismo Estado, entendiendo por tal el Estado social y democrático de Derecho en alguna de sus fórmulas o variantes posibles.

Cuando administrativistas y teóricos del Estado disputan entre sí, como es frecuente, acerca de las respectivas personalidades jurídicas de la Administración y del Estado, quizás la discusión no pase de constituir «una tempestad en la tetera académica». La prueba de ello es que la crítica de lo que Foucault bautizó como "el poder pastoral» —esto es, aquel poder que, so pretexto de garantizar y proteger nuestros derechos, nos oprime como todo poder lo suele hacer, amén de convertirnos en coartada para que ese poder se perpetúe- irrita equitativamente a catedráticos de Derecho Administrativo y de Derecho Político, lo que constituye el mejor indicio de que algo tienen unos y

14 Cfr., por ejemplo, Claus OfFE y Ulrich PREUSS, «Instituciones democráticas y recursos morales", Isegoria, 2, 1990, págs. 45-74 y, en el mismo número la revista, Francisco CoLOM GONZÁLEZ, "Legitimidad y democracia: dos décadas de un debate inconcluso», págs. 162-9. 
otros en común. Pero para lo que sí nos podría servir la discusión es para ayudarnos a articular mejor eso que hemos venido llamando el ámbito de lo públi$c o$, al cual podríamos concebir como un continuo que abarcaría por este orden la sociedad civil no-institucionalizada, las instituciones juridico-administrativas y la política institucional propiamente dicha. El Estado gravita por igual sobre los dos últimos tramos, pero el penúltimo de ellos - pensemos, por ejemplo, en la Administración de Justicia- no necesita estar «institucionalmente politizado", aunque lo pueda estar por otras vías, como cuando el poder ejecutivo invade competencias del poder judicial, en cuyo caso corresponde a la ciudadanía o sociedad civil velar para que no ocurra así. $Y$ la actividad, en cambio, del Estado persigue abiertamente "objetivos políticos" con una intencionalidad que se halla ausente, o que debiera estarlo cuando menos, de las prácticas de la Administración.

Ahora bien, ¿̇se desprende de nuestra caracterización del individualismo ético que sólo el primer tramo del continuo es susceptible de consideración moral, en tanto que la vida del Estado habría de ser considerada desde una perspectiva ajena a la ética?

En su libro Etica y política de comienzos de los sesenta, José Luis L. Aranguren sugirió una línea de respuesta ${ }^{15}$ que — salvada la treintena larga de años que nos separa de ella - sigue siendo merecedora de atención. Aranguren distinguía allí tres niveles de la ética: en primer lugar, la ética personal o individual, que vendría a ser la base de toda ética; en segundo lugar, la ética interpersonal que se encargaría de regular las relaciones sociales concebidas como relaciones entre un ego y un alter, relaciones que abarcan desde las familiares a cuantas puedan darse en el contexto de lo que estamos entendiendo por sociedad civil (Aranguren otorgaba a esta ética el nombre de "ética de la alteridad", donde ese «otro" o ese alter podría lo mismo ser el "otro concreto" de Seyla Benhabib que el "otro generalizado" de Mead y el interaccionismo ${ }^{16}$ ); y en tercer lugar, por último, la ética impersonal a cuyo cargo correría la regulación de las relaciones sociales que tienen lugar en el plano político-institucional, donde el "otro" no pasa de ordinario de ser más que un innominado alius, pese a lo cual aquellas relaciones debieran hallarse penetradas de sentido moral,

15 J. L. L. ARANGUREN, Etica y politica, Madrid, 1963, cc. III-V.

16 Cfr. S. BenHabIB, Situating the Self. Gender, Community and Postmodernism in Contemporary Ethics, Nueva York, 1992, págs. 148 y ss. 
pues la impersonalidad no entraña ajenidad o "alienación" y los alii, yo entre ellos, que constituímos el conjunto de la sociedad podríamos concebirnos mutuamente como "aliados" más bien que como mutuamente indiferentes o incluso mutuamente hostiles (Aranguren hablaba a este respecto de "ética de la aliedad", dando a entender que se trata de la "ética pública" que el Estado tendría que fomentar promocionando la efectiva democratización de la vida social y transformándose él mismo en lo que por aquel entonces se llamaba "un Estado de justicia social»). ¿Cuál sería, dentro de dicho esquema, el lugar del individuo ante la ética pública ${ }^{17}$ ?

En mi opinión, la afirmación de que la ética individual se halla a la base de toda otra ética, y la vertebra, habría de ser entendida en su sentido literal, pues si el individualismo ético se concibe en el sentido que hemos venido proponiendo - y no como sinónimo de "egoísmo racional» o cualquier otra de esas formas de individualismo que proliferan al socaire de las tesis del auge de la privacidad, el declive de lo público y demás (en cuyo caso, no cabría hablar de una ética transpersonal, ni interpersonal ni impersonal, sino sólo del individuo puro y duro)-, es decir, si el individualismo parte de admitir que el individuo se da siempre "en relación" ${ }^{18}$ dentro de una comunidad o de una serie de comunidades, tan individuo sería yo como mi alter ego o los alii, esto es, mis conciudadanos. Y el individualismo ético no se contentaría con menos de aspirar a hacer posible, siquiera sea aproximativamente y a sabiendas de la extrema dificultad de realizar tal ideal, la "confluencia de la sociedad civil y la sociedad política", pues no otra cosa es lo que significa la progresiva "profundización en la democracia" - en la democracia representativa institucionalizada, puesto que hoy por hoy no parece haber otra- con el fin de hacerla cada día más participativa, de acuerdo con esa idea regulativa de la democracia a que Aranguren gusta de dar el nombre de democracia como moral en cuanto diferente de la democracia como institución o "democracia establecida» ${ }^{19}$. En último término, aquella aspiración recogería la rousseaniana de aproximar cuanto podamos al hombre y al ciudadano, cuyo común soporte es siempre el individuo, pero cuidando de invertir el sentido de dicha aproximación —que, para un cierto Rousseau al menos, procedía de izquierda a derecha más bien que a la inversa

17 Véase para más detalles mi trabajo "¿Qué es el individualismo ético?", en Márgenes, en prensa.

18 Cfr. ibid, así como el ensayo "Primado de la autonomía", Laguna, 2, 1993-94, págs. 7-30.

19 ARANGUREN, La democracia establecida: una crítica intelectuah Madrid, 1980. 
(lo que ha dado pie a tacharle de teórico de la "democracia totalitaria" y hasta de precursor del totalitarismo sin más, además de asignarle la paternidad del "mito de la identidad de sociedad civil y Estado" ${ }^{20}$ )—, puesto que el objetivo a perseguir no sería ya estatalizar a la sociedad civil sino, por así decirlo, sociocivilizar al Estado.

Aun si la terminología de Aranguren se presta a alguna que otra confusión, su "ética de la aliedad" o ética pública no debiera entenderse en ningún caso como sinónimo de "eticidad", que es como se traduce en español la Sittlichkeit que Hegel contraponía a la Moralität kantiana o "ética de los individuos». Para Hegel, según es bien sabido, el primado de la eticidad desembocaba en el reemplazamiento de la ética, puesto que no hay otra ética que la de los individuos, por la filosofía del Derecho, pero en Aranguren no se registra el menor asomo de un intento de sustituir la conciencia moral por el código civil y su ética pública se limita a reconocer que - a la altura de los tiempos en que nos encontramos- la sociedad se enfrenta a desafíos político-morales, como la defensa de las libertades o la procuración de crecientes cotas de igualdad, que el Estado social y democrático de Derecho (versión actualizada de su Estado de justicia social) tendría que ayudarnos a remontar. Y ello le lleva a atribuir a dicho Estado un activo papel en cuanto «agente de moralización» de la vida social que discurre para Aranguren por dos vías, una vía negativa o de "autolimitación del poder estatal» en la medida en que el Estado sea un auténtico Estado de Derecho y una vía positiva o de "realización de la justicia», de acercamiento del Derecho al Derecho justo, que implicaría al Estado en la democratización real y no sólo formal de la sociedad, lo que naturalmente no depende ya tanto del Estado en abstracto, de la política de Estado más o menos retóricamente recogida en las Constituciones vigentes, cuanto de las concretas políticas gubernamentales y de su mayor o menor grado de concordancia con las bases sociales que respalden a los respectivos gobiernos.

Cuando Aranguren proponía su modelo de «institucionalización de lo éticon a través del Estado, lo hacía en contraposición a dos modelos por aquellas fechas alternativos de semejante institucionalizacion. El primero de ellos, el modelo del comunismo autoritario de los países sedicentemente socialistas, cuyo teórico intento de asegurar la igualdad se hacía a costa de la

20 Véase «Más allá del contrato social», en Desde la perplejidad, cit., cap. 7, esp. págs. 263 y ss. 
libertad (por lo demás, hoy día sabemos que esa aseguración de la igualdad se reducía a poco más que una coartada para el mantenimiento del sistema, puesto que el "socialismo real" tenía bastante más de "real" que de "socialistaw). El segundo, el modelo del Estado de bienestar a la sazón en su apogeo en los países capitalistas de Occidente, donde la libertad prevalecía sobre la igualdad aunque lo que el sistema pretendía, con mayor o menor éxito, era paliar y hacer más llevaderas las desigualdades por medio de la generalización del consumo (en eso consistía el "bienestarismo" denostado entonces por la izquierda, que hoy se daría con un canto en los dientes ante la simple idea de su preservación, lo que sin duda constituye un llamativo ejemplo de aplicación de la Ley de Murphy a la interpretación del curso de la historia). La suerte de uno y otro modelo la conocemos bien: el "comunismo autoritario" se ha hundido estrepitosamente y el "Estado de bienestar" se halla en profunda crisis, cuando no en bancarrota (las consecuencias de esta última no pueden calibrarse aún, pero a juzgar por estallidos como los habidos hace escasos años en Los Angeles o más recientemente en Alemania, para colmo trufados de problemas érnicos y raciales, podrían no tener nada que envidiar al caos en el que están sumidas las zonas más conflictivas de la Europa del Este ex-comunista, como los Balcanes o el Cáucaso). En cuanto al Estado arangureniano de justicia social, continúa siendo una aspiración insatisfecha, que es en lo que consiste precisamente la "democracia como moral", si bien en los países europeos aquella aspiración ha de hacer frente a problemas que apenas se entreveían en los años sesenta, el más importante de los cuales acaso sea el de la presión que sobre las democracias industriales avanzadas o ya postindustriales ejerce hoy un Tercer Mundo sumido en el hambre y la desesperación, pero no obstante fuente todavía de importantes materias primas así como de abundante y barata mano de obra.

En España sin ir más lejos, convertidos como lo estamos en porteros de la Comunidad Europea, sabemos algo de eso. Los países europeos se resisten a conceder derechos de ciudadanía a la población inmigrante procedente el Tercer Mundo y vacilan entre la segregación cultural - con el pretexto de salvaguardar la propia «identidad" o la integración cultural forzosa de sus miembros, arrasando así su "diferencia», que para ellos, claro está, sería su identidad. La ideología que mejor expresa esa vacilación es una versión retrógada del «comunitarismo", según la cual el individuo - incluida su consideración como sujeto moral- no pasaría de constituir una entelequia al margen de la comunidad o del "nosotros" al que pertenece, un nosotros siempre delimitado frente a un 
"ellos", de suerte que, volviendo a Mandeville, lo que sean la virtud o el bien y el vicio o el mal vendrían entonces definidos por el éthos comunitario de turno, cuando no por el étnos y aun la raza (con lo que semejante comunitarismo tendría serias dificultades para explicar o justificar éticamente la convivencia política de distintas comunidades en el seno de nuestras actuales sociedades desarrolladas, crecientemente multiculturales además de mestizas o plurirraciales, y en las que aquella convivencia habría de articularse sobre la base de la "participación" democrática más bien que sobre cualquier género de "pertenencia" ajena a la decisión de los interesados). Frente a ese punto de vista se impondría, en consecuencia, la más absoluta tolerancia en materia de virtudes comunitarias o concepciones comunitarias del bien, pero lo cierto es que no basta con la tolerancia, pues - tengan o no derechos de ciudadanía- lo que aquellos inmigrantes habrían de tener,en cualquier caso, son derechos bumanos, algo que nuestros comunitaristas difícilmente podrían ver con buenos ojos, pues tampoco ha faltado entre ellos quien sostenga que creer en la existencia de "derechos humanos» es como creer que existen brujas o unicornios. Para cerrar con esta cuestión nuestro trabajo, ¿qué tendría que decir acerca de ella el individualismo ético?

Marx, de quien alguna vez pudo decirse que era un "individualista radical» secuestrado por el marxismo, criticó también en su día «la ideología de los derechos humanos", pero desde muy otros presupuestos que los del comunitarismo contemporáneo. La criticó, a saber, por la separación que establecía entre esos derechos del hombre y los del ciudadano, separación, en efecto, consagrada por la Asamblea de la Revolución Francesa en la mismísima Dèclaration des droits de l'homme et du citoyen ${ }^{21}$. En nuestros días, esa separación sigue vigente, como lo muestra el caso que acabamos de citar de los inmigrantes del Tercer Mundo, que ha llevado a hablar de "el extranjero" como una «herida abierta, o mal cicatrizada, entre el hombre y el ciudadano".

He aquí, por tanto, un buen ejemplo de problema de ética pública o "poli(é)tica» ${ }^{22}$, pues se trata indudablemente de una herida que tan sólo el

21 Cfr. Francisco José MARTfNeZ, "El extranjero como cicatriz entre el nombre y el ciudadano", Sistema, 113, 1993, págs. 73-90.

22 El concepto de poli(é)tica, acuñado por Pablo RODENAS de la Universidad de La Laguna ("Poli(é)tica, o el tránsito del interés a la legitimidad”, Laguna, 2, 1993-94, págs. 31-48), preside bajo su inspiración las andanzas de los colegas canarios que elaboran en las Islas la revista Disenso. 
Estado - un Estado social y democrático de Derecho- podría cauterizar con el concurso del individuo y de la sociedad civil, lo que requiere, por lo pronto, que el pensamiento de la izquierda reivindique su propia interpretación de esas nociones de "individuo" y "sociedad civil» en lugar de dejarla en otras manos, como hasta hoy ha venido sucediendo con más frecuencia de la deseable. 